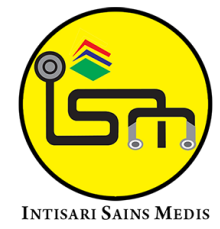

Published by Intisari Sains Medis

\section{Temuan radiologi dalam kelainan kongenital atresia jejunum: serial kasus}

\author{
Listyani Gunawan ${ }^{1 *}$, Pande Putu Yuli Anandasari ${ }^{2}$, Putu Patriawan ${ }^{3}$
}

\begin{abstract}
Background: Jejunoileal atresia is an emergency due to mechanical gastrointestinal obstruction, a rare case with a prevalence rate of $1-3$ per 10,000 births. There is no difference in incidence by gender. Delay in treatment results in huge losses in terms of malnutrition, failure to thrive, and even death. These case series aim to evaluate radiological findings in congenital jejunal atresia.

Case Presentation: There were 3 patients with the main complaint of bilious vomiting. These three patients underwent a plain abdominal $x$-ray examination, obtained a picture of a high total obstruction with a triple bubble picture, or had a dilated picture of the proximal obstruction. Partial obstruction based on plain radiographs in one of the patients was found, followed

by an examination of contrast meal which filled smoothly up to the jejunum segment with a windsock appearance. The three cases have been proven through surgery, various types of jejunal atresia were obtained. Intestinal resection was performed, followed by an end-to-end jejunal anastomosis.

Conclusion: Correct diagnosis determines the appropriate treatment for the patient. Plain abdominal radiograph as an initial examination in assessing total or partial obstruction in the jejunum, with a typical triple bubble or dilated bowel segment proximal to the obstruction. The windsock appearance of the jejunal segment on the contrast meal confirms the diagnosis of the jejunal web.
\end{abstract}

Keywords: Jejunal Atresia, Triple Bubble Appearance, Windsock Appearance, Jejunal Web, Apple Peel Appearance. Cite This Article: Gunawan, L., Anandasari, P.P.Y., Patriawan, P. 2021. Temuan radiologi dalam kelainan kongenital atresia jejunum: serial kasus. Intisari Sains Medis 12(3): 752-756. D0l: 10.15562/ism.v12i3.1116

\section{ABSTRAK}

'Program Pendidikan Dokter Spesialis Radiologi, Fakultas Kedokteran, Universitas Udayana, RSUP Sanglah, Bali, Indonesia;

${ }^{2}$ Dosen dan Konsultan Radiologi Anak, Departemen Radiologi, Fakultas Kedokteran, Universitas Udayana, RSUP Sanglah, Bali, Indonesia;

${ }^{3}$ Dosen dan Konsultan Radiologi Intervensi, Departemen Radiologi, Fakultas Kedokteran, Universitas Udayana, RSUP Sanglah, Bali, Indonesia;

\footnotetext{
*Korespondensi:

Listyani Gunawan;

Program Pendidikan Dokter Spesialis Radiologi, Fakultas Kedokteran, Universitas Udayana, RSUP Sanglah, Bali, Indonesia; listyani1992@gmail.com
}

Diterima: 20-08-2021

Disetujui: 02-10-2021

Diterbitkan: 19-10-2021
Latar Belakang: Atresia jejunoileal merupakan kegawatdaruratan akibat obstruksi mekanik gastrointestinal, yang merupakan kasus jarang dengan angka prevalensi 1-3 per 10000 kelahiran, tidak ada perbedaan insiden berdasarkan gender. Terlambatnya tatalaksana mengakibatkan kerugian yang besar baik malnutrisi, gagal tumbuh, hingga kematian. Laporan kasus ini bertujuan untuk mengevaluasi temuan radiologi dalam kelainan kongenital atresia jejunum. Laporan Kasus: Terdapat 3 pasien dengan keluhan utama muntah bilosa. Kemudian dari pemeriksaan foto polos abdomen didapatkan gambaran obstruksi total letak tinggi dengan gambaran triple bubble atau memiliki gambaran dilatasi dari proksimal obstruksi. Obstruksi parsial berdasarkan foto polos pada salah satu pasien, dilanjutkan pemeriksaan contrast meal yang mengisi lancar hingga segmen jejunum dengan windsock appearance. Ketiga kasus tersebut telah terbukti melalui hasil operasi, didapatkan atresia jejunum berbagai tipe. Dilakukan reseksi usus dilanjutkan anastomosis end-to-end jejunal.

Kesimpulan: Diagnosis yang tepat, menentukan tatalaksana yang sesuai bagi pasien. Foto polos abdomen sebagai pemeriksaan inisial dalam menilai obstruksi total atau parsial pada jejunum, dengan gambaran khas triple bubble atau dilatasi segmen usus proksimal dari obstruksi. Windsock appearance segmen jejunum pada contrast meal mempertajam diagnosis jejunal web.
Kata kunci: Atresia Jejuno, Gambaran Triple Bubble, Gambaran Windsock, Jejunal Web, Gambaran Apple-Peel. Sitasi Artikel ini: Gunawan, L., Anandasari, P.P.Y., Patriawan, P. 2021. Temuan radiologi dalam kelainan kongenital atresia jejunum: serial kasus. Intisari Sains Medis 12(3): 752-756. D0I: 10.15562/ism.v12i3.1116 


\section{PENDAHULUAN}

Muntah bilosa atau bilious vomiting merupakan tanda kegawatdaruratan pada neonatus dengan atau tanpa distensi abdomen. ${ }^{1}$ Diagnosis banding muntah bilosa pada neonatus dapat berasal dari kondisi sepsis berat maupun obstruksi mekanik gastrointestinal. ${ }^{1,2}$ Tatalaksana kedua kondisi tersebut berbeda, terapi empiris atau operasi. Obstruksi letak tinggi yang sering dikaitkan dengan kelainan kongenital diantaranya atresia duodenum, atresia jejunal-ileum, peritoneal band, dan malrotasi terjadi pada 1 dari 3000 kelahiran hidup. ${ }^{1,2}$ Berdasarkan beberapa contoh tersebut, kasus atresia jejunum merupakan kasus yang cukup jarang ditemukan. $^{3}$

Terlambatnya tatalaksana pada kasus kongenital atresia jejunum mengakibatkan kerugian dari sisi malnutrisi, gagal tumbuh hingga kematian. ${ }^{4}$ Peran radiologi sangat penting dalam membantu klinisi menegakkan diagnosis agar mendapatkan tatalaksana yang terbaik bagi pasien. ${ }^{4}$ Pemeriksaan radiografi abdomen sebagai pemeriksaan inisial sangat mudah dan cepat dilakukan serta dapat memberikan informasi penting adanya obstruksi pada saluran cerna. ${ }^{5}$ Obstruksi letak tinggi yang bersifat parsial dengan dilanjutkan menggunakan studi kontras semakin mempertajam dalam penegakan diagnosis. ${ }^{5}$

Ketiga kasus ini merupakan kelainan kongenital pada neonatus dengan klinis muntah bilosa yang diakibatkan oleh atresia jejunum. Serial kasus ini mengangkat tiga kasus kelainan kongenital atresia jejunum dimana diharapkan dapat meningkatkan pengetahuan adanya kelainan kongenital jejunum yang dapat didiagnosis dari pemeriksaan radiologi.

\section{LAPORAN KASUS}

\section{Kasus 1}

Bayi perempuan preterm berusia 8 hari dan berat badan lahir rendah (1590 gram), dengan keluhan muntah kehijauan sejak lahir. Pasien dekompresi menggunakan gastric tube sejak pasien lahir, residu kehijauan $20 \mathrm{cc}$ per 24 jam. Riwayat ekskresi mekonium dalam 24 jam pertama kehidupan dilakukan dengan colok dubur. Pasien lahir dari ibu P2A1 secara

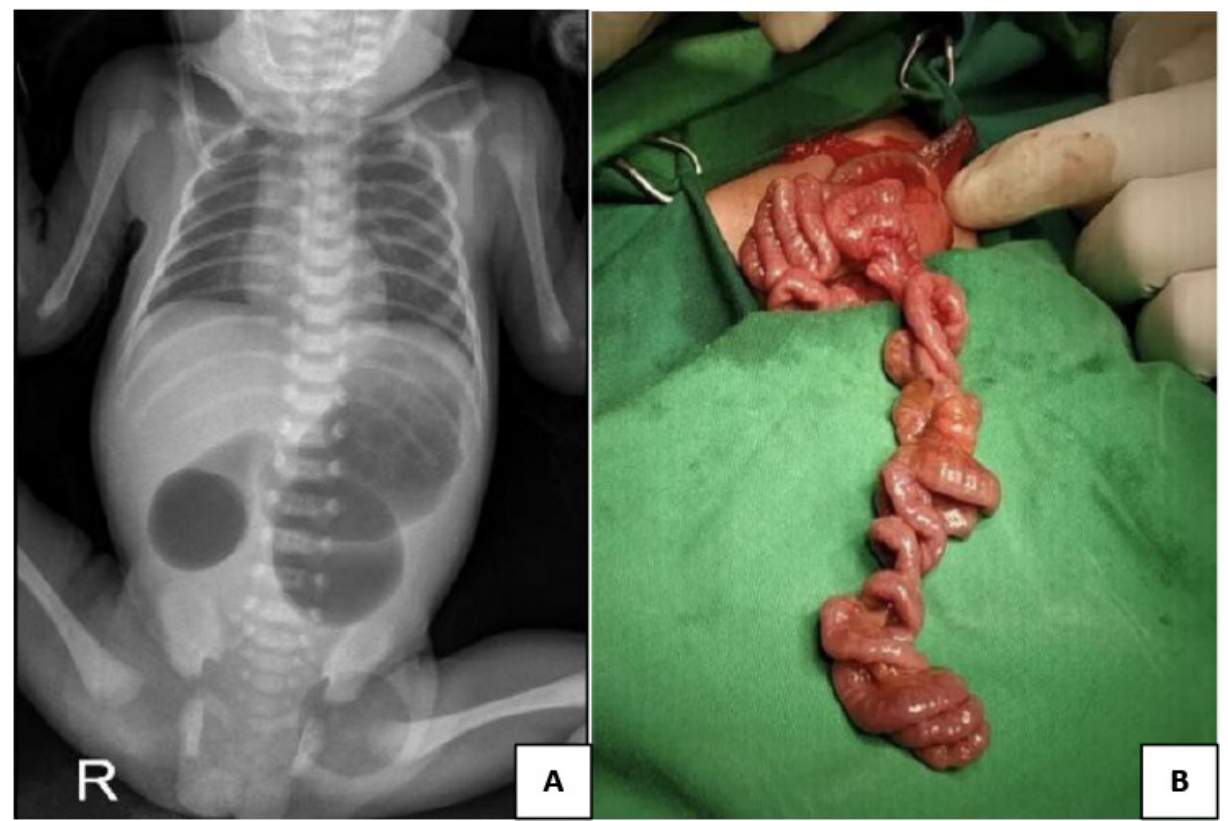

Gambar 1. (A) Triple bubble sign pada obstruksi total jejunum proksimal dan (B) Atresia jejunum dengan Apple peel appearance.
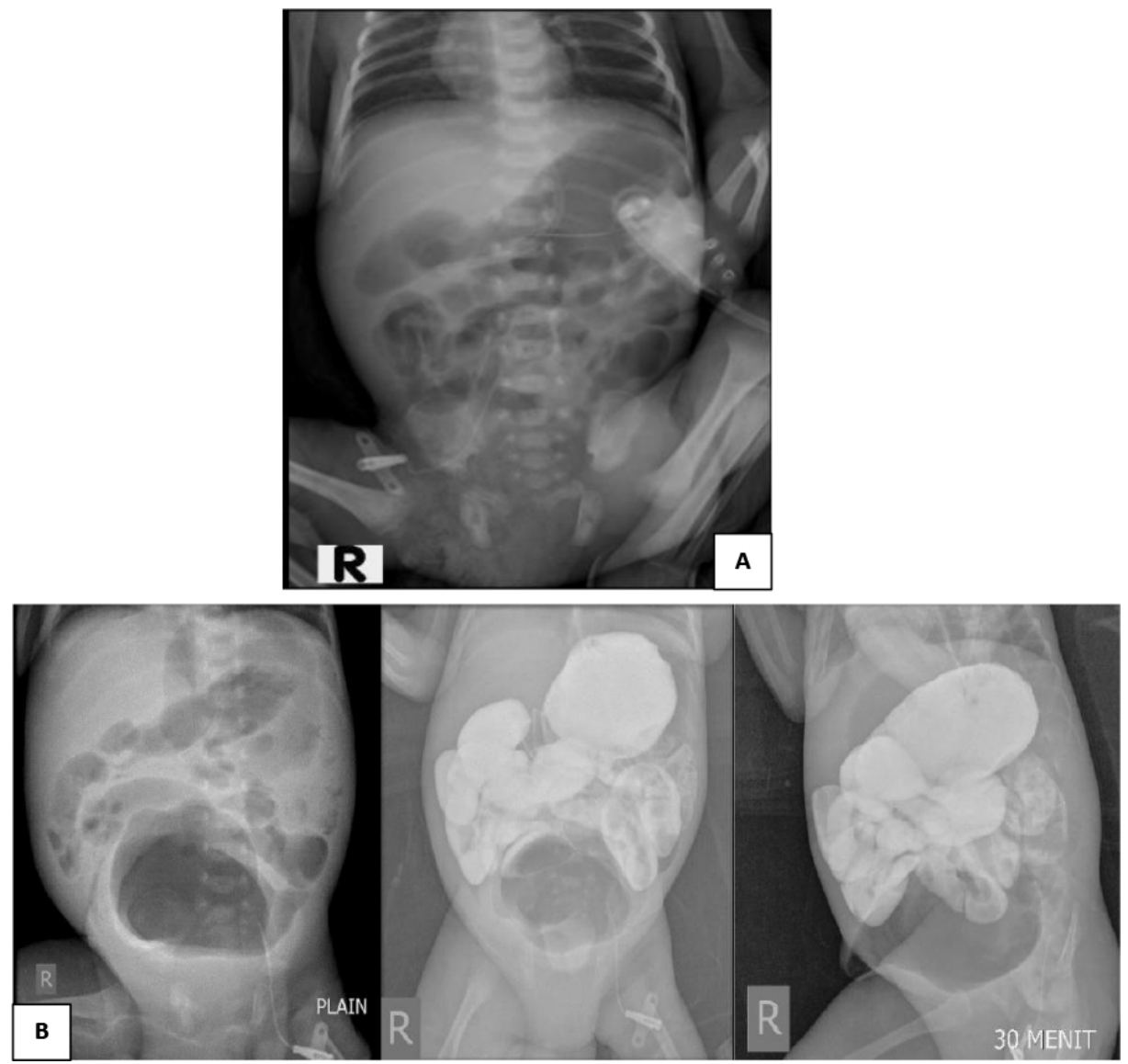

Gambar 2. (A) Foto Polos Abdomen menunjukkan obstruksi totalis segmen jejunum dan (B) Pemeriksaan Contrast meal hari ke 9 post operasi tampak kontras terhenti di segmen jejunum disertai dilatasi pada segmen jejunum distal. 


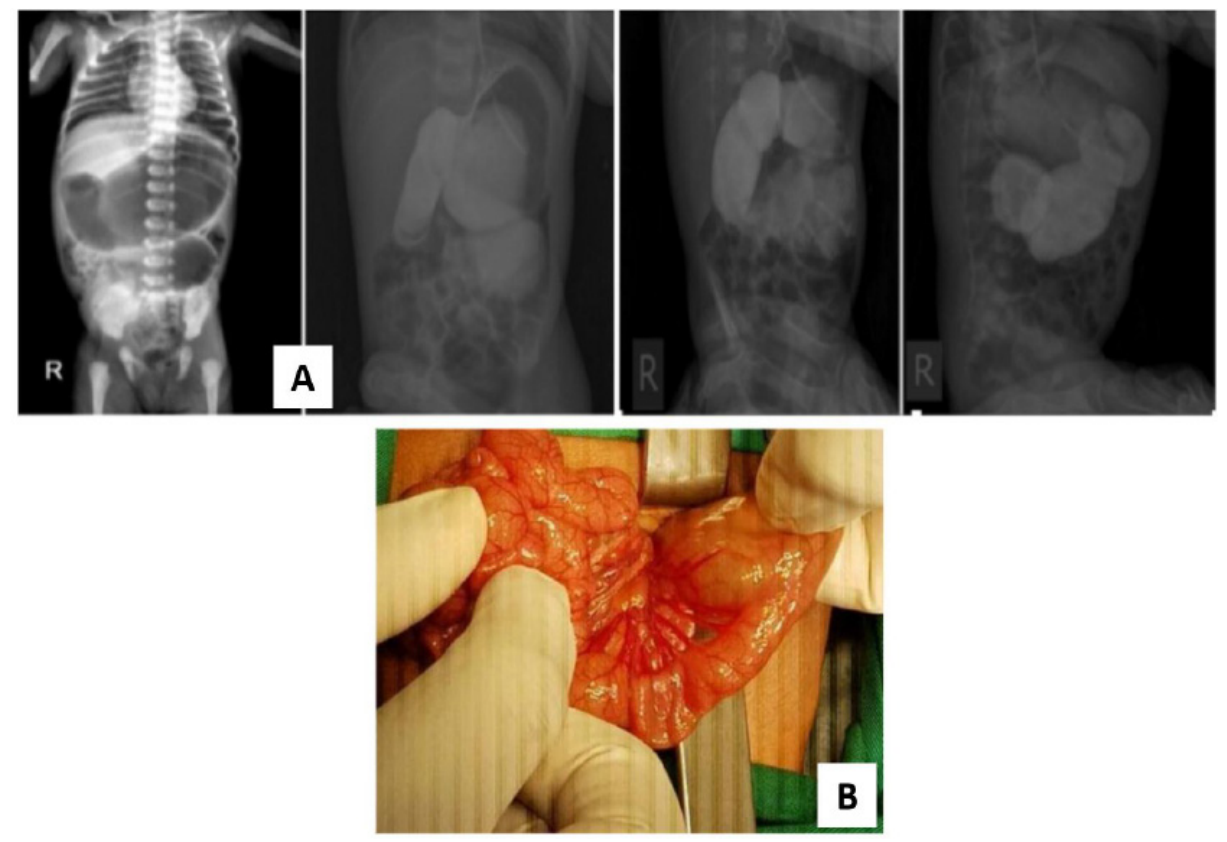

Gambar 3. (A) Pemeriksaan radiografi babygram dan contrast meal menunjukan parsial obstruksi setinggi jejunum dengan windsock appearance dan (B) Atresia jejunum tipe I (jejunal web).

spontan dengan pemeriksaan kehamilan secara rutin, tanpa pemeriksaan USG rutin. Pasien dilakukan pemeriksaan foto babygram dan didapatkan gambaran dilatasi gaster, duodenum dan sebagian segmen jejunum proksimal (triple bubble sign), tanpa adanya gambaran udara di distalnya maupun pneumoperitoneum (Gambar 1A). Pasien didiagnosa dengan curiga atresia jejunum. Dari operasi laparotomi didapatkan atresia jejunum tipe IIIB, dengan gambaran khas apple peel appearance (Gambar 1B). Reseksi jejunum dan jejunoje-junostomy dilakukan terhadap pasien ini.

\section{Kasus 2}

Bayi laki-laki berusia 6 hari dengan keluhan muntah bilosa disertai perut distensi sejak berusia 4 hari. Pasien lahir secara spontan, preterm, dan berat badan lahir sangat rendah (1400 gram). Riwayat eksresi mekonium dalam 24 jam kelahiran dengan colok dubur. Pasien juga mengalami distress pernapasan akibat Hyaline Membrane Disease (HMD) dan kelainan jantung kongenital berupa Atrial Septal Defect (ASD). Pasien merupakan anak pertama, dengan riwayat kontrol rutin kehamilan, polihidramnion disangkal.
Pasien dilakukan pemeriksaan radiografi babygram, didapatkangambaran dilatasi gaster dan tampak distribusi gas usus berakhir pada segmen jejunum, tanpa gambaran pneumoperitoneum, mengesankan suatu obstruksi dengan kecurigaan atresia jejunum (Gambar 2A) Operasi laparotomi dilakukan, eksisi jejunal web pada proksimal jejunum pada $\pm 10 \mathrm{~cm}$ dari ligamentum treitz. Selama perawatan, timbul fistula umbilical dan residu gastric tube kehijauan pada 7 hari post operasi. Pemeriksaan contrast meal dilakukan dengan kontras wamjt

zter soluble melalui gastric tube, tampak kontras terhenti pada sisterna usus halus yang berdilatasi pada proyeksi jejunum distal (Gambar 2B). Tindakan relaparotomy dilakukan, adhesiolisis, dan repair fistel. Pasien meninggal dalam masa perawatan dengan komorbid prematur, sepsis, distress pernapasan, dan ASD.

\section{Kasus 3}

Bayi perempuan berusia 11 hari dengan riwayat muntah kehijauan sejak 2 hari terakhir dan ikterik. Pasien merupakan anak pertama dari ibu P1A3 yang lahir secara spontan, dengan riwayat kelahiran aterm, berat badan lahir 2600 gram, pengeluaran mekonium dalam 24 jam setelah lahir. Pemeriksaan antenatal care rutin dilakukan oleh ibu pasien, tidak ditemukan polihidramnion.

Pasien dilakukan pemeriksaan babygram, tampak gambaran dilatasi gaster, duodenum, dan sebagian sisterna usus halus (jejunum), serta masih tampak distribusi udara hingga ke rektum. Dari foto ini mengesankan suatu partial small bowel obstruction, tanpa gambaran pneumoperitoneum. Selanjutnya dilakukan pemeriksaan contrast meal dengan menggunakan kontras water soluble melalui gastric tube. Kontras mengisi lancar pada gaster, duodenum yang berdilatasi, dan melambat pada pengisian fleksura duodenojejunal (Gambar 3A). Partial obstruksi akibat atresia jejunal menjadi diagnosa banding pada kasus ini. Dari tindakan laparotomi, dilakukan reseksi pada segmen usus dengan jejunal web dan dilakukan end-toend anastomosis (Gambar 3B).

\section{PEMBAHASAN}

Atresia jejunum merupakan kelainan kongenital yang $90 \%$ kasus terjadi hanya pada segmen jejunum saja tanpa dijumpai atresia pada segmen usus lain. Atresia jejunum merupakan suatu kasus yang jarang dengan angka prevalensi 1-3 per 10000 kelahiran di United States, baik jenis kelamin laki-laki maupun perempuan memiliki angka kejadian yang sama. ${ }^{3-6}$ Saat ini belum terdapat data spesifik prevalensi atresia jejunum di Indonesia. Kecurigaan atresia jejunum yaitu pada pasien dengan riwayat polihidramnion dari hasil ultrasonografi prenatal, prematur, dan berat badan lahir rendah..$^{1,6,7}$ Gejala klinis yang dialami pasien diantaranya muntah bilosa, distensi abdomen jika atresia pada distal jejunum/ileal, jaundice, ekskresi mekonium lebih dari 24 jam, tandatanda dehidrasi (penurunan urin output, takikardi, subfebris, iritabel, letargi hingga koma). ${ }^{1,4}$

Menurut kriteria Grosfeld modifikasi dari klasifikasi Louw, atresia jejunum dibagi menjadi 4 tipe, adanya web yang mengoklusi intralumen (tipe I), kedua ujung lumen buntu yang dihubungkan dengan cord usus fibrosa atretik (tipe II), kedua ujung lumen buntu disertai defek mesenteric berbentuk V (tipe IIIa), apple peel atresia atau Christmas-tree atresia (tipe 
IIIb), dan multiple atresia (tipe IV)., $1,5,8,9$ Menurut study sebelumnya, patofisiologi atresia diakibatkan infark iskemik multipel pada proses embriogenesisnya. ${ }^{1,6}$ Perkembangan abnormal notochord pada area perkembangan midgut, anomali vaskuler plasenta, imunodefisiensi kongenital atau didapat, herediter, penggunaan pseudoefedrine, ergotamine cafein, cocaine, nicotine pada masa kehamilan menjadi penyebab lain kondisi ini. ${ }^{1,3,6}$ Studi yang dilakukan Komuro et al, mendokumentasikan adanya kaitan anomali vaskuler plasenta, yang menyebabkan berat badan lahir rendah dan gangguan pertumbuhan fetal dengan atresia jejunum kompleks (tipe IIIa atau tipe IV). ${ }^{10}$

Pemeriksaan radiologis berperan dalam mendukung diagnosis. Dari radiografi polos abdomen setelah 4 jam kelahiran dapat dinilai adanya obstruksi partial maupun total. Obstruksi total akibat atresia jejunum tampak gambaran patogonomonik triple bubble yaitu dilatasi gaster, duodenum dan jejunum proksimal, tanpa adanya distribusi gas usus di distalnya. ${ }^{11,12}$ Studi Malhotra A et al., menunjukkan $47 \%$ neonatus dengan muntah bilosa memiliki temuan spesifik dari radiografi polos sehingga pasien dilakukan operasi. ${ }^{13}$ Pada obstruksi parsial pemeriksaan lanjutan dengan studi kontras contrast meal membantu dalam memperlihatkan lokasi atresia yang spesifik dan menyingkirkan diagnosa banding yang lain terkait tatalaksana yang berbeda. ${ }^{6,9,12}$

Jejunal web intraluminal sangat jarang ditemukan karena web intraluminal lebih sering dijumpai pada duodenum bagian akhir. ${ }^{8,14}$ Sesuai studi Lin $\mathrm{HH}$ et al., dimana menemukan kasus jejunal web pada $8 \%$ dari 37 kasus gastrointestinal web dalam kurun waktu 20 tahun terakhir. ${ }^{15}$ Jejunal web dengan obstruksi parsial, dengan pemeriksaan foto polos abdomen saja seringkali menimbulkan keraguan. Pada pemeriksaan kontras contrast meal didapatkan obstruksi parsial pada segmen jejunum dengan gambaran windsock appearance yang khas pada kasus jejunal web. Gambaran deformitas windsock jejunum merupakan anomali akibat elongasi pasif dari diverticulum intraluminal akibat peristaltik yang kontinyu, masih jarang ditemui pada literatur. ${ }^{16}$ Berbeda dengan kasus ke-2 dimana gambaran radiografi abdomen sudah dapat menggambarkan obstruksi total setinggi segmen jejunum. Pada operasi laparotomi, didapatkan jejunal web pada kedua kasus ini.

Pada kasus yang lebih jarang terjadi atresia jejunum tipe IIIB pada 11$32.4 \%$ kasus, terdiri dari atresia pada proksimal jejunum dekat ligamentum treitz dengan tidak adanya distal arteri mesenterika superior. Bagian distal usus halus membentuk spiral disekitar vaskuler seperti apple peel., ${ }^{4,6,15}$ Varian apple peel secara tipikal ditemui pada bayi prematur, berat badan lahir kurang, sering disertai malrotasi usus maupun kelainan kongenital lainnya. ${ }^{5,17}$ Kasus atresia jejunum dengan apple peel appearance dilaporkan berkaitan dengan familial dan autosomal resesif yang merupakan kasus anomali kongenital yang sangat serius. ${ }^{18}$ Pada kasus 1 yang merupakan bayi prematur dengan berat badan lahir rendah, keluhan muntah bilosa, kemudian dilakukan pemeriksaan plain foto babygram. Tampak gambaran triple bubble yaitu dilatasi gaster, duodenum dan jejunum proksimal akibat obstruksi total pada segmen jejunum. ${ }^{11}$

Langkah operatif terhadap kasus atresia jejunum telah membawa prognosis yang baik bagi bayi ditunjang dengan total parenteral nutrisi yang meningkatkan keberhasilan. Beberapa faktor yang masih berpengaruh dalam kejadian morbiditas dan mortalitas bayi dengan atresia jejunum diantaranya kelainan kongenital komorbid lainnya, distress pernapasan, prematur, short bowel syndrome, atau komplikasi post operasi seperti leakage area anastomosis, peritonitis, ileus. ${ }^{19}$

\section{SIMPULAN}

Diagnosa yang tepat dapat mengarahkan tatalaksana yang sesuai bagi pasien. Foto polos abdomen merupakan pemeriksaan awal yang dapat menunjukkan obstruksi total maupun parsial pada bayi dengan muntah bilosa. Gambaran khas yang dapat ditemukan berupa gambaran triple bubble, maupun dilatasi segmen proximal usus dari obstruksi. Gambaran windsock pada segmen jejunum pada pemeriksaan contrast meal mengarahkan kepada diagnosis jejunal web.

\section{KONFLIK KEPENTINGAN}

Penulis melaporkan tidak ada konflik kepentingan dalam penulisan serial kasus ini.

\section{ETIKA PENELITIAN}

Penulisan naskah ini telah mendapatkan persetujuan tertulis (Informed Consent) dari pasien yang berdasarkan pada kaidah etika publikasi dari pedoman COPE dan ICMJE.

\section{PENDANAAN}

Pada penulisan serial kasus ini, penulis bertanggung jawab terhadap pendanaan tanpa melibatkan sumber pendanaan dari pihak manapun.

\section{KONTRIBUSI PENULIS}

Keseluruhan penulis memiliki kontribusi yang sama dalam laporan kasus ini baik dari tahap penemuan kasus, pembacaan hasil radiologi kasus, maupun luaran klinis yang diperoleh dimana disampaikan dalam publikasi ilmiah.

\section{DAFTAR PUSTAKA}

1. Kimura K, Loening-Baucke V. Bilious vomiting in the newborn: rapid diagnosis of intestinal obstruction. Am Fam Physician. 2000;61(9):2791-2798.

2. Tang PMY, Leung YCL, Hung JWS, Liu CCW, Chung KLY, Chao NSY, et al. Jejunal web masquerading as intestinal malrotation in a neonate with bilious vomiting: A case report. J Pediatr Surg Case Reports. 2015;3(7):292-294.

3. Rajendran R, Elsalam H, Hegab S, Mukttash G. Multiple jejunoileal and colonic atresias: Case report and review of the literature. Saudi Surg J. 2014;2(2):66-69.

4. Wax JR, Hamilton T, Cartin A, Dudley J, Pinette MG, Blackstone J. Congenital jejunal and ileal atresia: natural prenatal sonographic history and association with neonatal outcome. J Ultrasound Med. 2006;25(3):337-342.

5. Maglinte DD, Kelvin FM, Sandrasegaran K, et al. Radiology of small bowel obstruction: contemporary approach and controversies [. Abdom Imaging. 2005;30(2):160-178.

6. Janugade H, Agarwal S, Bane P, Patil R, Garje A, Singh V, et al. Windsock Deformity in Jejunal Obstruction. International Journal of Health Sciences and Research. 2014;4(2):226-30.

7. Dao DT, Demehri FR, Barnewolt CE, Buchmiller TL. A new variant of type III jejunoileal atresia. J Pediatr Surg. 2019;54(6):1257-1260.

8. Baba AA, Shera AH, Sherwani AY, Bakshi IH. Neonatal intestinal obstruction due to double 
jejunal web causing Windsock deformity. J Indian Assoc Pediatr Surg. 2010;15(3):106-107.

9. Abba SM, Ismail A, Hamisu DA. Neonatal intestinal obstruction: A case of jejunal colonic atresia with micro colon. West African Journal of Radiology. 2012;19(1):14-16.

10. Komuro H, Amagai T, Hori T, Hirai M, Matoba $\mathrm{K}$, Watanabe $\mathrm{M}$, et al. Placental vascular compromise in jejunoileal atresia. J Pediatr Surg. 2004;39(11):1701-5.

11. Vinocur DN, Lee EY, Eisenberg RL. Neonatal intestinal obstruction. AJR Am J Roentgenol. 2012;198(1):W1-W10.

12. Atresia PJ. The Triple Bubble Sign: A Neglected Radiologic Feature of Proximal Jejunal Atresia. The Internet J Radiol. 2012;3(1):1-6.

13. Malhotra A, Lakkundi A, Carse E. Bilious vomiting in the newborn: 6 years data from a Level III Centre. J Paediatr Child Health. 2010;46(5):259-261.

14. Upadhyaya VD, Kumar B, Gupta A, Naranje K, Singh A. Jejunal Windsock Deformity: A Rare Cause of Incomplete Neonatal Intestinal Obstruction. J Neonatal Surg. 2016;5(4):57.

15. Lin HH, Lee HC, Yeung CY, Chan WT, Jiang $\mathrm{CB}$, Sheu JC, et al. Congenital webs of the gastrointestinal tract: 20 years of experience from a pediatric care teaching hospital in taiwan. Pediatr Neonatol. 2012;53(1):12-7.

16. Weledji EP, Monono N, Nana T. Side-toside Anastomosis after Resection of Atresic Segment is Safe and Effective in the Incomplete Type 1 Jejunal Atresia. Clinics in SurgeryGastroenterological Surgery. 2020;5(1):1-3

17. Berrocal T, Lamas M, Gutieérrez J, Torres I, Prieto C, del Hoyo ML. Congenital anomalies of the small intestine, colon, and rectum. Radiographics. 1999;19(5):1219-1236.

18. Kurbet S, Mane R, Patil H, Bhandankar M, Dhaded S. Apple peel jejunal atresia: Successful management of a rare case. Journal of The Scientific Society. 2012;39(1):29-31.

19. Bracho-Blanchet E, González-Chávez A, Dávila-Pérez R, Zalles Vidal C, FernándezPortilla E, Nieto-Zermeño J. Prognostic factors related to mortality in newborns with jejunoileal atresia. Cir Cir. 2012;80(4):345-351.

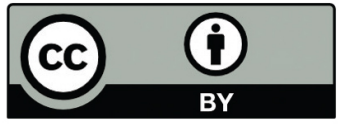

This work is licensed under a Creative Commons Attribution 